\title{
Organizational Generativity, Social Media and the Co-creation of Nonprofit Services: A Sociomateriality Perspective
}

\author{
Fatuma Namisango \\ University of Technology Sydney \\ fnamisango@gmail.com
}

\author{
Kyeong Kang \\ University of Technology Sydney \\ Kyeong.Kang@uts.edu.au
}

\author{
Junaid Rehman \\ University of Technology Sydney \\ Junaid.Rehman@student.uts.edu.au
}

\begin{abstract}
This paper presents the relationship between organizational generativity, nonprofits' use of social media, and the co-creation of nonprofit services. While anchoring to the sociomaterialism perspective, we analyze social media interactions of nonprofits by identifying social media affordances and symbolic expressions. To explain the hypothesized relationships, we conduct a survey of nonprofits using social media to co-create services. We applied structural equation modeling (SEM) techniques to generate measurement models and test our hypotheses. Our findings indicate that organizational generativity is positively related to social media affordances for nonprofits, the symbolic expressions of social media to nonprofits and service co-creation. We generally observe that organizations have to build the capacity to operate in new ways as a means of exploring the opportunities and possibilities offered by social media as well as leveraging social media interactions for service co-creation.
\end{abstract}

\section{Introduction}

The realm of social media spans all kinds of organizations and disciplines - organizations, as well as individuals, appropriate social media for unique purposes. While focusing on social media use in organizations, we need to recognize the differences in social media use driven by the scope, aim, culture, and nature of organizations. For instance, for-profit organizations are performance-oriented and focus on generating profits for founders and shareholders, while nonprofit organizations are public-serving organizations and focus on social value. The key performance indicators for social media use in the for-profit organization will mainly relate to ROI [1] while those of nonprofit will relate to donation growth, beneficiaries, and social contributions. Nonprofits tend to focus on public engagement and common social goals than the for-profit organization. This renders their social media use and aims ultimately different from those of profitoriented organizations as well as other types of organizations. This study focuses explicitly on nonprofit use of social media and nonprofit-public interaction in the creation and provision of nonprofit services.

For-profit organizations use social media as a marketing and customer relationship strategy aimed at improving sales and maximizing profits $[1,2]$. In nonprofits, social media is widely recognized for information sharing, community creation, collective action, maintaining relationships [3-5]. The key activities of nonprofits on social media and the associated outcome or consequence of such activities are not yet fully defined and illustrated. Social media also allows nonprofits to engage with the public in mobilizing and combining material and nonmaterial resources to provide nonprofit services [5], a practice technically known as service co-creation. Social media functionality, such as posts and comments are resources for engaging in value co-creation in nonprofits [6]. However, very few studies have considered nonprofit interaction with the public on social media as a service co-creation practice and the outcome of social media interactions [7].

Because nonprofits intentionally share information, build communities, call for action, and maintain relationships on social media, they attempt to leverage social media to foster their operations. It is important to note that social media offers opportunities for nonprofits to act in the ways they do, which are popularly noted as social media functions for nonprofits. We recognise that the above-mentioned functions are action possibilities or opportunities that emerge as nonprofits interact with the public using social media technology in their routine operations. When organisations use social media they require "capacities for action" [8] or "the capacity to act" [9] in ways that leverage the opportunities provided by social media to support their routine operations. It is important that actors - i.e., individuals, groups and organizations - have the ability to rejuvenate, reproduce and transform their actions (i.e., generativity or generative capacity) $[10,11]$. Earlier studies have not sufficiently discussed the capabilities required by organisations to make the most of social media and survive the dynamics of this environment. Consequently, the relationship between the organisation's generative capabilities, how organisations interact in technology enabled environments, and associated outcomes lacks an empirically motivated explanation. 
While many studies identify and present the functions of social media in nonprofits - i.e., technically social media affordances for nonprofits - many have not elaborated the nature and role of the organization's ability to reconfigure resources to produce new possibilities to challenge the normative status quo on social media. Moreover, such ability - i.e., generativity or generative capacity could enable organisations use technology in their routine operations and enabling technology afforded actions [12]. We, therefore, consider that it is important for the organization to recognize and consider its ability to challenge status quo and therefore transform its actions in a social media environment. We submit that generative capacity - as an attribute of an organization - helps a social organization to drive its interactions towards co-created social outcomes.

This study examines the interactions between nonprofits, the public, and social media as a context for (nonprofit) service co-creation with emphasis on the role of generativity. The research question underlying this study was how is organizational generativity related to nonprofit social media interactions and service cocreation? Our motivation to answer this question is twofold. First, it helps us to provide an empirical explanation of the relationship between social media use in nonprofits and the co-creation of services. Second, it also allows us to explain the role of the organization's ability to revitalize, rejuvenate, and produce new possibilities for action on social media.

The rest of the paper is organized as follows. We review potential forms of service co-creation enabled by social media in nonprofits. We also discuss generativity as an organization attribute in close relation to the aspect of organization dynamic capabilities. We provide the theoretical background of the study and the research model. We mention the methods used in the study, the findings, and then discuss our findings.

\section{Co-creation of Services}

Co-creation of services is "the activity, practice or process of jointly creating services in a specific business context" [13]. It involves resource integration and value realization among multiple engaging actors [14]. Like other co-creation processes, service co-creation is supported by space or platform of engagement [15]. With a space of engagement, service co-creation requires the organization to attract consumer involvement, participation, and engagement in the organization's service processes [13]. Service cocreation, depending on the context, will emerge in multiple interrelated forms $[13,16,17]$. There many forms of service co-creation as identified in different contexts, including the following.
Co-ideation represents a form of service co-creation through which the organization allows customers and other stakeholders to contribute ideas, view ideas, and track the implementation of ideas [17]. Co-ideation could involve other activities such as co-exploration, codiagnosing, and co-meaning creation. This is the most popular form of service co-creation reported in the literature and has been realized in service innovations [17], public service provision [18], and health care services [19]. For nonprofits on social media, coideation activities would particularly include sharing ideas, identifying potential ideas, and translating potential ideas into actions that mitigate community needs, service gaps, and possible improvements.

Co-initiation, which is usually the initial step towards the entire process of service co-creation. It relates to activities of customer involvement and contribution towards discovering service offering and solutions that create value for both the organization and the customer. Co-initiation is a popular form of service co-creation emerging in collaborative innovation and co-production of enhanced public service [20]. Coinitiation of nonprofit services would involve spurring community involvement in resource mobilization, tailoring services to certain outcomes, co-sensing the needs of the community, and gravitating towards meeting those needs [20].

Co-progression, which represents an ongoing process of, or set of activities for developing, reshaping and gradually advancing an organization's services or community development programs towards becoming more valuable and relevant to the organization's target community. Co-progression in this context is premised on the processes of co-design and co-development of services, which are inclined on defining service propositions and prerequisites. Social media could enable co-progression of services because such online communities have the potential to support the conceptualization of services [21]. Service co-creation forms such as co-development are evident in health care services [19].

Co-promotion, generally, involves activities of attracting two or more entities to launch a single product or service under the same brand name with the same price and a single marketing strategy. Service consumers are active co-promoters who improve the effectiveness and efficiency of promotion programs [19]. Co-promotion, a.k.a., co-launch is a key form in service innovation [17]. Co-promotion involves harnessing social media networks to increase service reach, utilizing shares and hashtags to increase awareness about the organization's services, running social media campaigns and advocacies, etc.

Co-delivery of services involves collaboration activities that bring actors together to employ resources, 
individually as well as collectively to enhance service consumption [16]. Service delivery would encompass aggregate activities such as co-financing and coimplementation, gathering people to get involved in the organization's events, attracting voluntary support, etc. For nonprofits, service consumers and the public at large could play the roles of productive resource and contributor to quality (relevance), satisfaction, and value.

Co-experiencing emerges as actors integrate resources over time and across multiple encounters to create shared experiences. Service experiences may occur as a process through multiple phases, an outcome of other elements of the service, or a phenomenon based on individuals' subjective interpretations of a service [22]. Co-experiencing is believed to influence the actor's overall co-creation experiences [23]. Social media provides a space for collective experiences gathered through sharing stories and experiences, engaging in similar events, deducing from others experiences and stories.

Social media creates a collaborative space for resource integration [24]. Social media posts, likes, feedback, etc., have thus enabled nonprofits to involve and engage the public in resource mobilization and integration [5]. It has enabled nonprofits to mobilize and integrate material resources such as donations and social resources such as networks and emotional support, thereby supporting the co-creation of nonprofit services. Besides, tangible or material donations, social media posts, comments, and feedback are key resources for service co-creation in nonprofits [6].

\section{Generativity - as an Organisation Attribute}

Generativity, also referred to as generative capacity, is "the ability to originate, produce or procreate" [11, 12]. It is the productive capacity that focuses on creating something beneficial and desirable [10]. Generativity is an ability driven by task, context, and goal [10-12].

The notion of generativity is rooted in the seminal work of Erikson and is fruitfully applied to social psychology [25], educational science [26], information systems [10], etc. In this study, we examine generativity through the social sciences perspective, where we recognize generativity as "a characteristic that can provoke and transform social reality and social action" [10].

Generativity involves "rejuvenating and reconfiguring, reframing the way we see and understand the world challenging status quo and generating fresh alternatives for social action $[10,11,27]$. It is a key characteristic of explorative creativity and innovation because it allows organizations to uncover new possibilities in the social world $[10,28]$. We identify four potential dimensions of organizational generativity that would support sociomaterial interactions on social media.

(1) Adaptive capability refers to the organization's ability to sense and respond to opportunities for action [29]. Sensing is the organization's ability to detect, capture, and interpret opportunities, while responding is the ability to reconfigure resources to react to the opportunities it senses [29]. Adaptive capability is also concerned with the organizational abilities of reactiveness, resilience, and incremental innovation [30]. Adaptivity is an important aspect of a generative organization because it allows the organization to identify emerging opportunities and respond to such opportunities by reconfiguring processes and resources to seize such opportunities towards new outcomes [29, $31]$.

(2) Learning capability, related to the view of generative learning, "emphasizes continuous experimentation and feedback in an ongoing examination of the very way organizations go about defining and solving a problem, surfacing assumptions and challenging beliefs and operating values" [28]. It is a cyclic and iterative process through an individual, a group, and the organization [32, 33]. The two key aspects of organization learning capability are; (a) openness to new ideas and experimentation, (b) acquisition, transfer, and integration of knowledge [28, 33].

(3) IT-business synergy is a key aspect of the organization's array of IT capabilities. IT capability is the ability to acquire, deploy, combine, or reconfigure IT resources to support strategy and work processes [34]. We particularly derive IT-business synergies from two aspects of IT capability - i.e., IT-business spanning capability, which is the ability to "envision and exploit IT resources to support business objectives" and IT proactive stance which is the ability to "search for new ways to embrace IT innovations to create new opportunities" [34]. IT-business synergies would then refer to the organization's ability to identify, select, and leverage IT opportunities to support creativity, innovativeness, and productivity in the organization's activities.

(4) Relational capability relates to the organization's ability to scope and realize opportunities embedded in its relationships and networks [35]. Relational capabilities involve key abilities such as relationship learning and relationship behavioral capability. Relationship learning is the ability to generate knowledge and stimulate cognitive activity that allows the organization to appropriately manage its relations, improve its network oriented practices as well as predict and prepare for future relationship needs [36]. 
Relationship behavioral capability is the ability to foster collaboration, adjust to new relationships and changes relationship collaboration, flexibility, and change [36]. These aspects of relational capability "capture the output of adaptive and generative learning, verifying both the dissemination of new relationship management knowledge and resulting action" [36].

\section{Theoretical Underpinnings and Research Model}

This study adopts the technology affordances lens to empirically analyze the role of social media materiality in nonprofits and generally explain the sociomateriality of social media in the way nonprofits act and interact with the public on social media, and with social media. The technology affordances perspective is rooted in the sociomateriality theoretical lens [12, 37] and therefore exploring social media affordances allows us to provide some insights into the interactions between a nonprofit organization - as an actor - and social media - as an artifact.

The sociomaterial lens explains the relationship between humans and artifacts by arguing that the social and the material are constitutively entangled in practice [9]. The sociomaterial lens privileges neither the technocentric approach, which focuses on how technology affects human actions nor the human-centric approach that focuses on human interpretation of, and interaction with, a technology. It advocates for the recognition of a constitutive entanglement of the social and the material, which represents the assortment of human and material agencies [9].

The theory of affordances is rooted in ecological studies of [38]. Affordances are "opportunities for action" offered by a technology artifact [39]. Actions being the things that we intentionally do, and such these things - i.e., actions - have physical and social consequences or associated outcomes [39]. Now, because "affordances are opportunities for action, then they mirror the structure of actions ... in all kinds of descriptions" [39]. Technology affordances, in particular, are "action possibilities and opportunities that emerge from actors engaging with a focal technology" [37]. Considering technology affordances is a promising approach to rectify the short-comings of the techno-centric and human-centric approaches [37, $40,41]$ and a useful approach to analyzing social interactions in the technology world [37].

However, the structure of technology in sociomaterial interactions, not only offer opportunities for action but also communicates meaning and values to the user, which is conceptually referred to as symbolic expressions (SE) about the functionality of a technology
[41-43]. Symbolic expressions are "communicative possibilities offered by a technical object for a specific user group" $[41,43]$. Although less attention is given to $\mathrm{SE}$, they shape the functional affordances (FA) of a technology towards the user's ultimate actions $[41,43]$. Symbolic expressions of a technical object will emerge in two ways - by communication of meaning and communication of values.

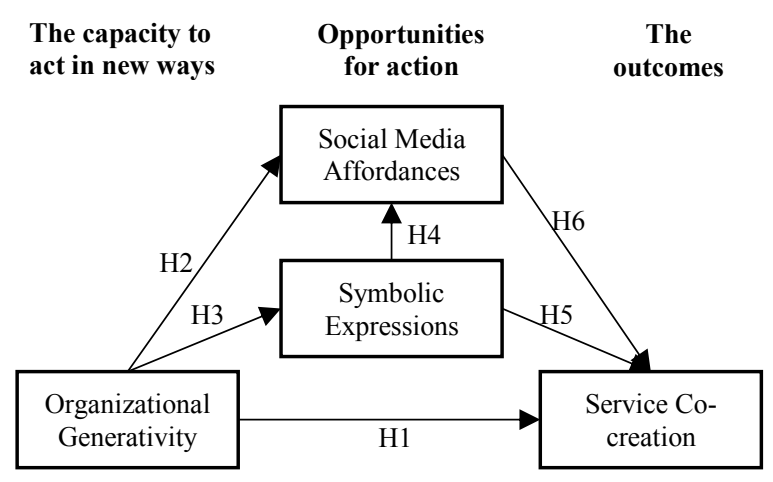

Figure 1. Research Model

Generativity involves openness to ideas, experimentation, and risk-taking actions [28]. It supports exploration and exploitation of creativity and innovativeness in collectives $[10,11,28]$. This could be because it involves continuous learning, inquiry and dialogue, collaboration, and collective vision [44]. Ultimately, generativity shapes collective outcomes [11].

H1: Organizational generativity is positively related to social media enabled service co-creation in nonprofits.

Generativity shapes collective acts and patterns of conduct [11]. It shapes social reality and social action $[10,11,27]$. It builds the drive to revitalize one's possibilities in a given context [10-12]. In technologysupported environments or sociomaterial interactions, for example, generativity is associated with perception and realization of the designed, improvised, and emergent technology affordances [12]. We, therefore, hypothesize that,

H2 - 3: Organizational generativity is positively related to social media affordances for, and its symbolic expressions to nonprofits.

Social media, as an artifact, shapes how we conceive this technology during sociomaterial interactions [45]. Symbolic expressions could be positively related to the object function [43]. Symbolic expressions as communicative possibilities of social media convey symbols recognizable and identifiable by users, which enable the user to understand and interact with its functions [43]. Communicative possibilities of an artifact, such as communication of object-related values, shape - and are themselves shaped by - the action 
possibilities afforded by the object [41-43]. We, therefore, hypothesize that,

H4: The symbolic expressions (communicative possibilities) of social media are positively related to social media affordances (useful and perceived functions)

Social media shapes how we conceive it and apply its functions to achieve our social and economic goals [45]. Users conceive and understand social media functionality through its symbolic expressions, which not only shape its affordances for the user but also the user's ultimate actions $[41,43]$. Social media conveys some meaning and values that could shape the actions for all actors involved in collective or collaborative action. Moreover, social media is inherently a system of symbols and signs [46] and will thus evoke a user's interest in collaborative, creative, co-creative, and innovative activities [47, 48].

H5: The symbolic expressions (communicative possibilities) of social media are positively related to service co-creation in nonprofits

Technology affordances are a foundation for ultimate social outcomes [43]. Because social media affordances relate closely to collective acts, they could be key to the overall collective outcome [11]. Social media particularly allows nonprofits to mobilize resources from the public [5], which is a step towards service co-creation [48]. It also supports public involvement, participation, and engagement [49], which are key pillars of service co-creation [13].

H6: Social media affordances (useful and perceived functions) are positively related to service co-creation in nonprofits.

\section{Research Method and Data Analysis}

We took a positivistic outlook to investigate our research question. Adapting a quantitative and deductive approach, we operationalised our variables basing on existing theoretical underpinnings and existing empirical evidence. This was important in providing valid evaluation and hypothesis testing using structural equation modeling [50]. The variables of this study were operationalized as shown in Table 1 below.

Table 1. Theoretical and Empirical Basis of Measurement Items used in the Questionnaire

\begin{tabular}{|c|c|c|c|}
\hline Construct & Sub-constructs & $\begin{array}{l}\text { No. of } \\
\text { measurement } \\
\text { items }\end{array}$ & $\begin{array}{l}\text { Theoretical and } \\
\text { Empirical Basis }\end{array}$ \\
\hline \multirow{3}{*}{$\begin{array}{l}\text { Social Media Affordances } \\
\text { (SMA) }\end{array}$} & Socialising (SOC) & 3 & {$[51-53]$} \\
\hline & Information Sharing (ISH) & 3 & {$[54-56]$} \\
\hline & Visibility (VIS) & 3 & {$[51,53,57]$} \\
\hline \multirow{2}{*}{$\begin{array}{l}\text { Symbolic Expressions of } \\
\text { Social Media (SESM) }\end{array}$} & Communication of Value (COV) & 3 & {$[41,43]$} \\
\hline & Communication of Meaning (COM) & 3 & {$[41,43]$} \\
\hline \multirow{4}{*}{$\begin{array}{l}\text { Organizational } \\
\text { Generativity (OG) }\end{array}$} & IT-Business Synergies (IB) & 3 & {$[58]$} \\
\hline & Relational capability (RC) & 3 & {$[35,59]$} \\
\hline & Adaptivity (AD) & 3 & {$[29,60]$} \\
\hline & Learning capability (LC) & 4 & {$[61,62]$} \\
\hline \multirow{6}{*}{ Service co-creation (SCC) } & Co-ideation & 3 & \multirow{5}{*}{$\begin{array}{l}\text { Self-developed items } \\
\text { basing on }[13,17]\end{array}$} \\
\hline & Co-initiation & 3 & \\
\hline & Co-progression & 3 & \\
\hline & Co-promotion & 3 & \\
\hline & Co-delivery & 3 & \\
\hline & Co-experiencing & 3 & $\begin{array}{l}\text { Self-developed items } \\
\text { basing on }[22,23]\end{array}$ \\
\hline
\end{tabular}

The objective of the study largely informs the sampling method, sample size, and the extent to which one can make statistical inference and generalization [63]. To apply structural equation modelling for model estimation and evaluation, we had to ensure that 'each of the units or cases in the population has an equal probability of being included in the sample to be studied' [50]. This makes a simple ransom sample the most appropriate method of sampling for our study. We, therefore, generated a random sample of seventy-three (73) nonprofit organizations. We developed a sampling frame of nonprofits in Uganda published on HelloUganda.com and commonwealthofnation.org. Our sampling frame comprised of 295 organizations. We selected and contacted 169 organizations using random numbers generated using Ms. Excel. We determined that 
169 nonprofits were sufficient basing on sampling tables by [64]. We sought organizational consent, and seventythree organizations agreed to participate in our study. Individual participants were recruited through management.

We gathered 289 usable responses resulting in $72.2 \%$ response rate. The surveyed organizations were operating in education and research services (42.5\%), social services $(54.8 \%)$, and health services $(13.7 \%)$. Majority of organizations have been in operation $2-10$ years $(50.7 \%)$ or over 10 years $(34.2 \%)$. Many were medium sized $(43.8 \%)$, while others were large organizations $(32.9 \%)$ or small organizations $(23.3 \%)$.

We applied covariance-based structural equation modeling to test our research model. We applied ML estimation with bootstrapping and item parceling to minimize the biases associated with multivariate nonnormal distribution $[65,66]$. We concluded model fit based on the 2-index strategy (CFI $\geq 0.95$ and SRMR < 0.08 ) by [67], which is recommended for minimizing type I errors [65, 67]. We also considered RMSEA < 0.08 to detect misspecified models $[65,67]$.

\section{Results}

\subsection{Measurement Model and Reliability}

By running a confirmatory factor analysis (CFA), we derive the measurement model for organizational generativity, social media affordances, symbolic expressions, and service co-creation. We assessed the reliability and validity of constructs using Cronbach's alpha, composite reliability (CR), and average variance extracted (AVE). We applied the Fornell Larcker Criterion and concluded convergent validity when AVE $>0.5$ or not significantly less than 0.5 with $\mathrm{CR}>0.7$, and concluded discriminant validity when AVE $>$ square correlation between two constructs. Tables $1-4$ present the reliability analysis for measurement models.

Table 2. A Second-Order Model of Organization Generativity (OG)

\begin{tabular}{|c|c|c|c|c|c|c|c|c|}
\hline \multirow[t]{2}{*}{ Measures of OG } & \multirow{2}{*}{$\begin{array}{l}\text { Factor } \\
\text { Loading }\end{array}$} & \multirow[t]{2}{*}{ Cronbach } & \multirow[t]{2}{*}{ CR } & \multirow[t]{2}{*}{ AVE } & \multicolumn{4}{|c|}{ Square Correlation } \\
\hline & & & & & IB & RC & AD & LC \\
\hline IT-Business Synergies (IB) & 0.71 & 0.74 & 0.96 & 0.60 & - & & & \\
\hline Relational capability (RC) & 0.81 & 0.82 & 0.98 & 0.61 & 0.34 & - & & \\
\hline Adaptivity (AD) & 0.82 & 0.80 & 0.97 & 0.57 & 0.35 & 0.44 & - & \\
\hline Learning capability (LC) & 0.74 & 0.77 & 0.95 & 0.63 & 0.28 & 0.35 & 0.37 & - \\
\hline
\end{tabular}

Table 3. A Three-Factor Model of Social Media Affordances (SMA)

\begin{tabular}{|c|c|c|c|c|c|c|}
\hline \multirow[t]{2}{*}{ Measures of SMA } & \multirow[t]{2}{*}{ Cronbach } & \multirow[t]{2}{*}{ CR } & \multirow[t]{2}{*}{ AVE } & \multicolumn{3}{|c|}{ Square Correlation } \\
\hline & & & & VIS & ISH & SOC \\
\hline Visibility (VIS) & 0.74 & 0.96 & 0.51 & - & & \\
\hline Information sharing (ISH) & 0.70 & 0.95 & 0.50 & 0.03 & - & \\
\hline Socializing (SOC) & 0.72 & 0.96 & 0.50 & 0.14 & 0.28 & - \\
\hline
\end{tabular}

Table 4. A Two-Factor Model of Symbolic Expressions of Social Media (SESM)

\begin{tabular}{|l|l|l|l|l|l|}
\hline Measures of SESM & Cronbach & CR & AVE & \multicolumn{2}{|c|}{ Square Correlation } \\
\cline { 4 - 6 } & & & & COM & COV \\
\hline Communication of meaning (COM) & 0.70 & 0.87 & 0.61 & - & \\
\hline Communication of values (COV) & 0.68 & 0.87 & 0.48 & 0.16 & - \\
\hline Model fit: CFI $=1$; SRMR $=0.01 ;$ RMSEA $=0 ; \chi^{2}=0.8, d f=1, \chi^{2} / d f=0.82$, Bollen-Stine $p=.37$ \\
\hline
\end{tabular}

Table 5. A Five-Factor Model of Service Co-creation (SCC)

\begin{tabular}{|l|l|l|l|l|l|l|l|l|}
\hline Measures of SCC & Cronbach & \multirow{2}{*}{ CR } & AVE & \multicolumn{4}{|c|}{ Square Correlation } \\
\cline { 5 - 7 } & & & & COI & COL & COP & COG & COX \\
\hline
\end{tabular}




\begin{tabular}{|l|l|l|l|l|l|l|l|l|}
\hline Co-ideation (COI) & 0.67 & 0.95 & 0.51 & - & & & & \\
\hline Co-delivery (COL) & 0.87 & 0.99 & 0.72 & 0.00 & - & & & \\
\hline Co-promotion (COP) & 0.81 & 0.97 & 0.70 & 0.40 & 0.06 & - & & \\
\hline Co-progression (COG) & 0.71 & 0.93 & 0.56 & 0.08 & 0.20 & 0.14 & - & \\
\hline Co-experience (COX) & 0.66 & 0.94 & 0.49 & 0.41 & 0.00 & 0.30 & 0.17 & - \\
\hline Model fit: CFI = 0.951; SRMR $=0.04 ;$ RMSEA $=0.79 ; \chi^{2}=90.9, d f=34, \chi^{2} / d f=2.68$, Bollen-Stine $p=.01$ \\
\hline
\end{tabular}

According to Tables 1 to 4 , all measurement models achieved sufficient internal consistency with the majority of Cronbach's alpha values above the recommendable value of 0.7 and composite reliability values above 0.75 . The measurement models also achieved sufficient convergent validity with AVE greater than or close to 0.5 , and discriminant validity with all AVE greater than the square correlations between constructs.

\subsection{Structural Model and Hypothesis Testing}

The structural model yielded satisfactory model fit at $\mathrm{CFI}=0.997$; $\mathrm{SRMR}=0.02 ; \mathrm{RMSEA}=0.059 ; \chi^{2}=$ $3.9, d f=2, \chi^{2} / d f=1.94$, Bollen-Stine $p=0.224$. The regression weights, significance levels and squared correlations are shown in Figure 2.

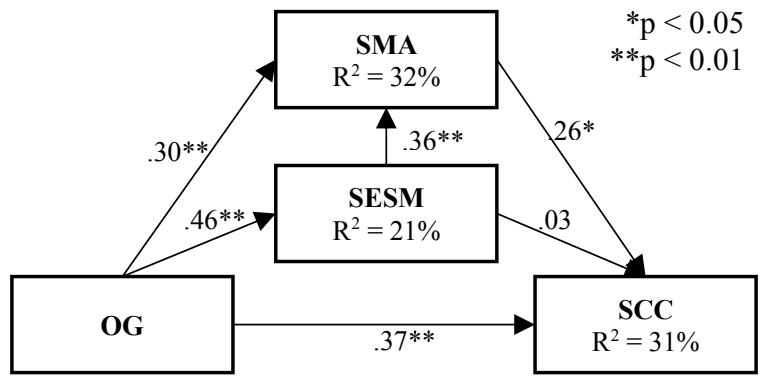

Figure 2. Structural Model

Table 5 below provides a summary of hypothesis testing by indicating hypothesized paths with corresponding standardized regression weights and commenting on whether or not the hypothesis is supported by the data.

\section{Table 6. Hypothesis Tests}

\begin{tabular}{|l|l|l|l|}
\hline Hn & Relations & $\boldsymbol{\beta}$ & Supported? \\
\hline H1 & OG $\rightarrow$ SCC & $0.37^{* *}$ & Yes \\
\hline H2 & OG $\rightarrow$ SMA & $0.30^{* *}$ & Yes \\
\hline H3 & OG $\rightarrow$ SESM & $0.46^{* *}$ & Yes \\
\hline H4 & SESM $\rightarrow$ SMA & $0.36^{* *}$ & Yes \\
\hline H5 & SESM $\rightarrow$ SCC & 0.03 & No \\
\hline H6 & SMA $\rightarrow$ SCC & $0.26^{*}$ & Yes \\
\hline$*$ p $<0.05 ; * * p<0.01$ & \\
\hline \multicolumn{4}{|l}{} \\
\hline
\end{tabular}

We found that organizational generativity is positively related to service co-creation $(\beta=0.37 ; \mathrm{p}<$ $0.01)$, social media affordances $(\beta=0.30 ; p<0.01)$ and symbolic expressions of social media $(\beta=0.46 ; p<$ 0.01 ), which supports $\mathrm{H} 1, \mathrm{H} 2$ and $\mathrm{H} 3$. Symbolic expressions are positively related to social media affordances $(\beta=0.36 ; \mathrm{p}<0.01)$ but not significantly related to service co-creation $(\beta=0.03 ; p>0.05)$. In turn, social media affordances are positively related to service co-creation $(\beta=0.26 ; p<0.05)$. We, therefore, found evidence to support $\mathrm{H} 4$ and $\mathrm{H} 6$ but not $\mathrm{H} 5$. We note that there is a stronger relationship between organizational generativity and symbolic expressions than with social media affordances.

\section{Discussion}

With regard to our research question, we note that organizational generativity is positively and significantly related to service co-creation on social media and the organization's social media structure defined by its affordances and symbolic expressions. First, our results suggest that organizations ought to build the capacity to rejuvenate and reframe the way they view the world or the environment within which they operate as a way towards (1) expanding the organization's action possibilities of social media. (2) Enhancing their interpretation and understanding of social media functionality to enable its goals, and (3) shaping the organization's standards of judgment about its goals and behavior on social media. Such capacity would include IT-business synergy, relational capability, adaptivity, and learning capability.

Secondly, we observed five forms of nonprofit service co-creation that emerge through social media. Our results suggest that nonprofits can attract and involve the public in service co-creation forms such as co-ideation, co-promotion, co-delivery, coprogression, and co-experiencing of nonprofit services through using social media. It is important to note that, the capacity to rejuvenate and reframe the way the organization views the world or the environment within which it operates contributes towards service co-creation on social media. Additionally, the organization's action possibilities of social media are also crucial in enabling service co-creation. Such action possibilities mainly include information 
sharing, socializing and increasing visibility and building a reputation.

Lastly, like other technologies, social media conveys some meaning about its functionality that is perceived uniquely by nonprofits; for example, understandability of certain functions. It also communicates certain values, such as transparency and consistency, which induce specific behaviors among nonprofits. Such perceived meaning and values may not directly shape the organization's co-creative activities, but it will certainly shape the apparent and actual action possibilities of social media to the organization. Moreover, such action possibilities, in turn, shape service co-creation.

\section{Limitations and Directions for Future Research}

This study focused on nonprofit use of social media for service co-creation, with particular reference to the role of organizational generativity. All evidence provided explains the effects of organizational generativity on social media use for service co-creation. Since co-creation processes are multi-actor engagements, further studies may investigate the role of the public, and other actors, in social media enabled service co-creation among nonprofits. Second, other studies may contribute by investigating and drawing comparisons basing on evidence from for-profit organizations. Such comparisons could present differing forms of service co-creation enabled by social media in for-profit organizations. Lastly, other studies may also show the distinctive social media affordances in for-profit organizations. Social media affordances in the forprofits could differ because affordances are shaped by the organization's aims and desired goals, which are certainly different from those of nonprofits. The effects of social media affordances on ultimate outcomes of using social media could differ across individuals, organizations, and sectors.

\section{Conclusion}

In this paper, we present the link between organizational generativity, social media possibilities and co-creation of nonprofit services as an explanation aimed at improving our understanding of social media use in nonprofits as well as offering additional insight to sociomaterial interactions. We examine this link by applying quantitative approaches to data collection and data analysis. Overall, our results are largely consistent with the hypothesized model and mainly demonstrate that IT-business synergy, relational capability, adaptivity and learning capability support social media affordances and service co-creation as an ultimate goal of social media use in nonprofits. It is important to note, however, that this study focused mainly on organizationsocial media interaction. It could be insightful if future research considered the organization-public patterns of interaction on social media, as alternative shapers of service co-creation on social media.

\section{References}

[1] Kaske, F., M. Kugler, and S. Smolnik. "Return on investment in social media--Does the hype pay off? Towards an assessment of the profitability of social media in organizations", in 2012 45th Hawaii International Conference on System Sciences, IEEE, 2012.

[2] Rishika, R., et al., "The effect of customers' social media participation on customer visit frequency and profitability: an empirical investigation", Information systems research, 24(1), 2013, pp. 108-127.

[3] Anagnostopoulos, C., et al., "Stakeholder Communication in 140 Characters or Less: A Study of Community Sport Foundations", VOLUNTAS: International Journal of Voluntary and Nonprofit Organizations, 28(5), 2017, pp. 2224-2250.

[4] Lovejoy, K. and G.D. Saxton. "Information, community, and action: How nonprofit organizations use social media", Journal of Computer-Mediated Communication, 17(3), 2012, pp. 337-353.

[5] Zhou, H. and Q. Pan. "Information, Community, and Action on Sina-Weibo: How Chinese Philanthropic NGOs Use Social Media", VOLUNTAS: International Journal of Voluntary and Nonprofit Organizations, 27(5), 2016, pp. 2433-2457.

[6] Sorensen, A., L. Andrews, and J. Drennan. "Using social media posts as resources for engaging in value co-creation: The case for social media-based cause brand communities", Journal of Service Theory and Practice, 27(4), 2017, pp. 898-922.

[7] Namisango, F., K. Kang, and J. Rehman. "What Do We Know about Socail Media in Nonprofits? A Review", in Pacific Asian Conference on Information Systems, Xi'an, China, AIS eLibrary, 2019.

[8] Suchman, L.A., Human-machine reconfigurations: Plans and Situated Actions, ed, ed., Cambridge University Press, Cambridge, 2007.

[9] Orlikowski, W.J., "Sociomaterial practices: Exploring technology at work", Organization studies, 28(9), 2007, pp. 1435-1448.

[10] Avital, M. and D. Te'Eni. "From generative fit to generative capacity: exploring an emerging dimension of information systems design and task performance", Information systems journal, 19(4), 2009, pp. 345-367.

[11] van Osch, W. and M. Avital. "Generative Collectives", in ICIS, 2010.

[12] Van Osch, W. and O. Mendelson. "A typology of affordances: Untangling sociomaterial interactions through video analysis", 2011. 
[13] Oertzen, A.-S., et al., "Co-creating servicesconceptual clarification, forms and outcomes", Journal of Service Management, 29(4), 2018, pp. 641-679.

[14] Hilton, T., T. Hughes, and D. Chalcraft. "Service cocreation and value realisation", Journal of Marketing Management, 28(13-14), 2012, pp. 1504-1519.

[15] Ramaswamy, V. and K. Ozcan, The Co-Creation Paradigm, ed, ed., Stanford University Press, Redwood City, UNITED STATES, 2014.

[16] Frow, P., A. Payne, and K. Storbacka. "Co-Creation: A Typology and Conceptual Framework ", in $A N Z M A C$, Perth, WA, 2011.

[17] Russo-Spena, T. and C. Mele. "“Five Co-s" in innovating: a practice-based view", Journal of Service Management, 23(4), 2012, pp. 527-553.

[18] Nambisan, S. and P. Nambisan, Engaging citizens in co-creation in public services: lessons learned and best practices, ed, ed., IBM Center for the Business of Government, 2013.

[19] Agrawal, A.K. and Z. Rahman. "Roles and resource contributions of customers in value co-creation", International Strategic Management Review, 3(1-2), 2015, pp. 144-160.

[20] Sørensen, E. and J. Torfing. "Co-initiation of collaborative innovation in urban spaces", Urban Affairs Review, 54(2), 2018, pp. 388-418.

[21] Sigala, M., "eCRM 2.0 applications and trends: The use and perceptions of Greek tourism firms of social networks and intelligence", Computers in Human Behavior, 27(2), 2011, pp. 655-661.

[22] Helkkula, A., "Characterising the concept of service experience", Journal of Service Management, 22(3), 2011, pp. 367-389.

[23] Verleye, K., "The co-creation experience from the customer perspective: its measurement and determinants", Journal of Service Management, 26(2), 2015, pp. 321-342.

[24] Singaraju, S.P., et al., "Social media and value cocreation in multi-stakeholder systems: A resource integration approach", Industrial Marketing Management, 54, 2016, pp. 44-55.

[25] Gergen, K.J., Realities and relationships: Soundings in social construction, ed, ed., Havard University Press, 1994.

[26] Yorks, L., "Adult learning and the generation of new knowledge and meaning: Creating liberating spaces for fostering adult learning through practitioner-based collaborative action inquiry", Teachers College Record, 107(6), 2005, pp. 1217-1244.

[27] Gergen, K.J., Toward Transformation in Social Knowledge, 2nd ed, ed., Sage Publication, Inc., London, 1994.

[28] Stacey, M. Generativity in Organization Life. 2014.

[29] Trinh-Phuong, T., A. Molla, and K.J. Peszynski. "Enterprise System-Enabled Organizational Agility Capability: A Construct And Measurement Instrument", in PACIS, 2012.

[30] Kharabe, A.T., Organizational agility and complex enterprise system innovations: A mixed methods study of the effects of enterprise systems on organizational agility, in School of Graduate Studies. 2012, Case Western Reserve University.

[31] Wei, L.-Q. and C.-M. Lau. "High performance work systems and performance: The role of adaptive capability", Human Relations, 63(10), 2010, pp. 14871511.

[32] Morgan, R.E. and P. Berthon. "Market orientation, generative learning, innovation strategy and business performance inter-relationships in bioscience firms", Journal of Management Studies, 45(8), 2008, pp. 13291353.

[33] Jerez-Gómez, P., J. Céspedes-Lorente, and R. ValleCabrera. "Organizational learning capability: a proposal of measurement", Journal of Business Research, 58(6), 2005, pp. 715-725.

[34] Lu, Y. and K. Ramamurthy. "Understanding the link between information technology capability and organizational agility: An empirical examination", Mis Quarterly, 2011, pp. 931-954.

[35] O'Toole, T. and H. McGrath. "Implementing a relational capability framework through an SME network", in IMP-conference, Uppsala, Sweden, 2008.

[36] Jarratt, D., "Conceptualizing a relationship management capability", Marketing Theory, 4(4), 2004, pp. 287-309.

[37] Faraj, S. and B. Azad, The materiality of technology: An affordance perspective, in Materiality and organizing: Social interaction in a technological world, P.M. Leonardi, B.A. Nardi, and J. Kallinikos, Editors. 2012, Oxford University Press: Oxford. p. 237-258.

[38] Gibson, J.J., The Theory of Affordances, in Perceiving, acting, and knowing: Toward an ecological psychology R.E. Shaw and J. Bransford, Editors. 1977, Lawrence Erlbaum Associates, Inc.: Hillsdale, NJ. p. 67-82.

[39] Pols, A.J.K., "Characterising affordances: The descriptions-of-affordances-model", Design Studies, 33(2), 2012, pp. 113-125.

[40] Leonardi, P.M. and S.R. Barley. "Materiality and change: Challenges to building better theory about technology and organizing", Information and Organization, 18(3), 2008, pp. 159-176.

[41] Markus, M.L. and M.S. Silver. "A foundation for the study of IT effects: A new look at DeSanctis and Poole's concepts of structural features and spirit", Journal of the Association for Information systems, 9(10/11), 2008, pp. 609.

[42] Cheikh-Ammar, M., "The IT artifact and its spirit: a nexus of human values, affordances, symbolic expressions, and IT features", European Journal of Information Systems, 2018, pp. 1-17.

[43] Grgecic, D., R. Holten, and C. Rosenkranz. "The Impact of functional affordances and symbolic expressions on the formation of beliefs", Journal of the Association for Information Systems, 16(7), 2015, pp. 580.

[44] Yang, B., K.E. Watkins, and V.J. Marsick. "The construct of the learning organization: Dimensions, measurement, and validation", Human resource development quarterly, 15(1), 2004, pp. 31-55.

[45] Orlikowski, W.J. and C.S. Iacono. "Research commentary: Desperately seeking the "IT" in IT 
research-A call to theorizing the IT artifact", Information systems research, 12(2), 2001, pp. 121134.

[46] Ellul, J., "Symbolic function, technology and society", Journal of social and biological structures, 1(3), 1978, pp. 207-218.

[47] Petrilli, S., "Meaning, metaphor, and interpretation: Modeling new worlds", Semiotica, 2006(161), 2006, pp. 75 - 118.

[48] Namisango, F. and K. Kang. "Social Media, Organisation-Community Relationships and Cocreation: A Case of Nonprofit Organizations", in Americas Conference on Information Systems, New Orleans, Louisiana, AIS eLibrary, 2018.

[49] Cho, M., T. Schweickart, and A. Haase. "Public engagement with nonprofit organizations on Facebook", Public Relations Review, 40(3), 2014, pp. 565-567.

[50] Bentler, P.M. and C.-P. Chou. "Practical issues in structural modeling", Sociological Methods \& Research, 16(1), 1987, pp. 78-117.

[51] Kietzmann, J.H., et al., "Social media? Get serious! Understanding the functional building blocks of social media", Business Horizons, 54(3), 2011, pp. 241-251.

[52] Treem, J.W. and P.M. Leonardi. "Social media use in organizations: Exploring the affordances of visibility, editability, persistence, and association", Annals of the International Communication Association, 36(1), 2013, pp. 143-189.

[53] Mathiesen, P., W. Bandara, and J. Watson. "The affordances of social technology: a BPM perspective", in Proceedings of 34th International Conference on Information Systems, Association of Information Systems-AIS, 2013.

[54] Abhari, K., E.J. Davidson, and B. Xiao. "Measuring the perceived functional affordances of collaborative innovation networks in social product development", in HICSS-49, IEEE, 2016.

[55] Abhari, K., E.J. Davidson, and B. Xiao. "Co-innovation platform affordances: Developing a conceptual model and measurement instrument", Industrial Management \& Data Systems, 117(5), 2017, pp. 873-895.

[56] O'Riordan, S., J. Feller, and T. Nagle, Exploring the affordances of social networking sites: An analysis of three networks, in ECIS 2012: 20th European Conference on Information Systems. 2012, (AIS Electronic Library (AISeL).

[57] Zheng, Y. and A. Yu. "Affordances of social media in collective action: the case of Free Lunch for Children in China", Information Systems Journal, 26(3), 2016, pp. 289-313.

[58] McLaughlin, S.A., "Dynamic capabilities: taking an emerging technology perspective", International Journal of Manufacturing Technology and Management, 31(1-3), 2017, pp. 62-81.

[59] McGrath, H., Developing a relational capability construct for SME network marketing using cases and evidence from Irish and Finnish SMEs. 2008, Waterford Institute of Technology.

[60] Lin, H.-F., J.-Q. Su, and A. Higgins. "How dynamic capabilities affect adoption of management innovations", Journal of Business Research, 69(2), 2016, pp. 862-876.

[61] Zahra, S.A. and G. George. "Absorptive capacity: A review, reconceptualization, and extension", Academy of management review, 27(2), 2002, pp. 185-203.

[62] Hughes, T., "Co-creation: Moving towards a framework for creating innovation in the Triple Helix", Prometheus, 32(4), 2014, pp. 337-350.

[63] Onwuegbuzie, A.J. and K.M. Collins. "A typology of mixed methods sampling designs in social science research", The qualitative report, 12(2), 2007, pp. 281316.

[64] Krejcie, R.V. and D.W. Morgan. "Determining sample size for research activities", Educational and psychological measurement, 30(3), 1970, pp. 607-610.

[65] Byrne, B.M., Structural Equation Modeling with AMOS : Basic Concepts, Applications, and Programming, Third Edition, ed, ed., Routledge, London, UNITED KINGDOM, 2016.

[66] West, S.G., J.F. Finch, and P.J. Curran, Structural Equation Models With Nonnormal Variables: Problems and Remedies, ed, Structural Equation Modeling: Concepts, Issues, and Applications, ed. R.H. Hoyle, Sage Publications Inc, 1995.

[67] Hu, L.t. and P.M. Bentler. "Cutoff criteria for fit indexes in covariance structure analysis: Conventional criteria versus new alternatives", Structural equation modeling: a multidisciplinary journal, 6(1), 1999, pp. $1-55$. 